\title{
Why the data tell us nothing about the importance of increasing returns to scale and externalities to capital
}

\author{
Jesus Felipe $^{1}$ \\ John McCombie ${ }^{2}$
}

\begin{abstract}
It has long been known that, because of aggregation problems and the Cambridge Capital Theory Controversies, the aggregate production function cannot theoretically exist. Nevertheless, the concept is still widely and uncritically used, presumably because it gives good statistical fits to the data with plausible results. It is shown that this occurs because of the existence of an underlying accounting identity. A suitable mathematical transformation of this identity ensures that it is always possible to specify an "aggregate production function" where the putative output elasticities equal the factor shares, even though the aggregate production does not exist. This is illustrated by reference to a simulation exercise by Felipe and McCombie (2006) and a study by Oulton and O'Mahony (1994). The latter reject the hypothesis that capital is "special", in that their regression estimates demonstrate that the "output elasticity" of capital does not significantly differ from its factor share. However, it is shown in this paper why the data could not have given any other result.
\end{abstract}

\section{Introduction}

The concept of the aggregate production function is at the heart of neoclassical growth theory and, indeed, of most of neoclassical macroeconomics. Yet, for well over half a century it has been known that the aggregate production function cannot theoretically exist, even as an approximation. This nihilistic conclusion results from the so-called "aggregation debate" which considers the conditions under which micro-production functions can be aggregated to give a well-behaved aggregate production function. ${ }^{3}$ Fisher (2005, p. $\left.489-490\right),{ }^{4}$ who has probably done more work than most on this problem, summarised the implications as follows.

Briefly, an examination of the conditions required for aggregation yields results such as:

(1) At the Asian Development Bank, Manila, Philippines and is Associate Member, Cambridge Centre for Economic and Public Policy, Department of Land Economy, University of Cambridge, UK. The paper reflects solely the opinions of the authors and does not necessarily reflect those of the Asian Development Bank, its Executive Directors, or those of the countries that they represent.

(2) Director of the Cambridge Centre for Economic and Public Policy, Department of Land Economy, University of Cambridge, UK.

(3) For a recent survey, see Felipe and Fisher (2003)

(4) See also Fisher (1992). 
- Except under constant returns, aggregate production functions are unlikely to exist at all.

- Even under constant returns, the conditions for aggregation are so very stringent as to make the existence of aggregate production functions in real economies a non-event. This is true not only for the existence of an aggregate capital stock but also for the existence of such constructs as aggregate labor or even aggregate output.

- One cannot escape the force of these results by arguing that aggregate production functions are only approximations. While, over some restricted range of the data, approximations may appear to fit, good approximations to the true underlying technical relations require close approximation to the stringent aggregation conditions, and this is not a sensible thing to suppose.

Further problems arise from the Cambridge Capital Theory Controversies of the 1960s and 1970s, although the issue was first given prominence by Joan Robinson (1953-54). This showed clearly how none of the results of the "neoclassical parable" held once one moved out of a one-commodity world (Cohen; Harcourt, 2003a). The two critiques are related, although Cohen and Harcourt (2003b, p. 232) argue that "the aggregation debate is a development within neoclassical theory and its applications, whereas much of the Cambridge, England, critique is from without, regarding the basic neoclassical intuition, robustness in more general models and appropriate methods". Nevertheless, both critiques serve to show just how flimsy are the foundations of the aggregate production function.

While both these criticisms were briefly acknowledged in textbooks and surveys in the 1970s, any reference to them has now completely disappeared from the current literature. This is notwithstanding that there has been no convincing refutation of the criticisms - at least we have yet to see any. The criticisms have simply been assumed away or ignored. Textbooks and surveys that did include a discussion of the aggregation problem and the Capital Controversies include Wan (1971), Nadiri (1970), Jones (1974), and Hacche (1979). ${ }^{5}$ Yet there is no mention of them in later textbooks and surveys such as Maddison (1987), Barro and Sala-iMartin (1995), Valdés (1990), Jones (1998), Aghion and Howitt (1998), and Weil (2004). ${ }^{6}$

So why is the aggregate production function so widely and uncritically used? The answer seems to involve a form of Friedman's (1951) methodological instrumentalism. All theories, so the argument goes, involve heroic abstraction and

(5) Hacche (1979) did not include a discussion about the aggregation problems.

(6) There is a passing mention to the aggregation problem in Temple (1999). 
unrealistic assumptions, but what matters is their predictive ability. The aggregate production function passes this test with flying colours. The problem with this defence is that the estimation of a putative aggregate production function cannot provide any valid inferences about the values of the parameters of the production function (i.e., the output elasticities and the aggregate elasticity of substitution) or the rate of technical change. This is because, empirically, constant-price monetary data have to be used as measures for output and capital and an underlying accounting identity precludes any meaningful estimation or test of an aggregate production function.

The implications are far reaching. The existence of the constant-price value accounting identity means that, through a suitable mathematical transformation of this identity, any estimation of a putative aggregate production can be made to give a perfect fit to the data. The results must show supposed constant returns to scale and output elasticities equalling their respective factor shares. This will occur even though the aggregate production function undoubtedly does not exist and, for example, individual firms may be subject to substantial returns to scale and subject to oligopolistic competition.

This is not a new critique, but first came to prominence buried in Phelps Brown's (1957) criticism of Douglas's cross-industry regression results (see, for example, Douglas, 1948). ${ }^{7}$ But rudimentary elements of it can be traced back to Bronfenbrenner (1944) and Marshak and Andrews (1944). The critique was later formalised by Simon and Levy (1963) and Shaikh $(1974,1980,1987)$ generalised it to time-series estimation of "production functions". Simon (1979a) also considered the criticism in the context of both cross-section and time-series data and thought it serious enough to mention it in his Nobel Prize lecture (Simon, 1979b). The criticism was revived and extended by Felipe and McCombie in a number of papers. See Felipe and Adams (2005), Felipe and McCombie (2001, 2003, 2005a, 2005b, 2006, 2007), Felipe (2001a, 2001b), Felipe and Holz (2001), McCombie (1987, 1998a, 1998b, 2000, 2000-2001, 2001), McCombie and Dixon (1991) and McCombie and Thirlwall (1994). The critique as applied to crosssection data was also "rediscovered" by Samuelson (1979).

While Cramer (1969), Wallis (1973) and Intriligator (1978) in their econometric textbooks and Walters (1966) in his survey on production and cost functions have mentioned the argument, none pushed it to its logical conclusion: namely, that it invalidated any attempt to test or estimate the aggregate production function, per se. (See McCombie, 1998a, for a discussion.) Solow (1974, 1987), it

(7) Saying that it came to prominence is perhaps a little over enthusiastic as the argument hardly attracted any attention at the time and has only been cited in a handful of papers since. But that is true of the critique in general. 
is true, did attempt refutations of a couple of aspects of the critique, but these are not compelling (Shaikh, 1980, Felipe and McCombie, 2005a).

Nevertheless, in what has been seen as an important study, Oulton and O'Mahony (1994, ch. 7) putatively test the hypothesis of the existence of increasing returns using growth data and the production function approach for UK manufacturing industries for various sub-periods over 1954-1986. Their results rejected the null hypothesis that there are externalities to capital as they also found that the estimated output elasticity of capital did not significantly differ from its factor share. Indeed, this was true of the other inputs.

The conclusions of this research have been cited on a number of occasions by, for example, Crafts et al. , as having important policy implications. They argue that

it seems that for physical capital these [externalities] are trivial (Oulton and O'Mahony, 1994)", (Crafts and Toniolo, p.1996, p.32); "moreover, recent work at the NIESR has found no evidence that social returns were significantly larger than private returns to fixed capital formation in British Manufacturing (Oulton and O’Mahony, 1994)" (Bean and Crafts, 1996, p.136); "Oulton and O'Mahony (1994), in an econometric analysis of British manufacturing during 1954-86, found that there was no support for the hypothesis that weighting capital by profits share underestimates capital's role in growth... (Crafts, 1996, p. 38).

However, in this paper we show why the data could not have failed to reject the null hypothesis that there are externalities to capital. Consequently, Oulton and O’Mahony's (1994) regressions can shed no light on this issue.

The paper is structured as follows. We begin by briefly recapitulating the general argument as to why the existence of an underlying identity precludes the estimation of an aggregate production function. We then discuss one of Felipe and McCombie's (2006) simulation exercises where they demonstrate how the estimation of a cross-industry production function using value data must give constant returns to scale, even though it is known that the individual production functions are subject to increasing returns to scale. Finally, in the light of these arguments we turn to Oulton and O'Mahony's results and show why they had to find the results that they did.

\section{Aggregate production functions and the accounting identity}

In neoclassical production theory, the production function in its most general form is written as:

$$
Q_{t}=f\left(K_{t}, L_{t}, t\right)
$$

where $Q, K, L$, and $t$ are output, capital, labour, and a time trend that acts a proxy for technical change. Theoretically, $Q$ and $K$ should be measured in 
homogenous physical units, as equation (1) is a technological relationship. It may be expressed in growth rates as:

$$
\hat{Q}_{t}=\lambda_{t}+\alpha_{t} \hat{K}_{t}+\beta_{t} \hat{L}_{t}
$$

where $\alpha$ and $\beta$ are the output elasticities of capital and labour and $\lambda$ is the rate of technical change. The symbol $\wedge$ above a variable denotes a growth rate.

If there are constant returns to scale, perfect competition, and firms are paid their marginal products, then it can be simply shown that the following holds:

$$
\hat{Q}_{t}=\lambda_{t}+a_{t} \hat{K}_{t}+\left(1-a_{t}\right) \hat{L}_{t}
$$

where $a$ is capital's factor share and (1-a) is the share of labour, and $a=\alpha$ and (1a) $=\beta$.

From Euler's theorem, output may be written as:

$$
Q_{t}=f_{K t} K_{t}+f_{L t} L_{t}=r_{t}^{\prime} K_{t}+w_{t}^{\prime} L_{t}
$$

where $r^{\prime}$ is the price of each machine and $w^{\prime}$ is the wage rate, both measured in commodity terms. Equation (4) expressed in growth rates is:

$$
\hat{Q}_{t}=a_{t} \hat{r}_{t}^{\prime}+\left(1-a_{t}\right) \hat{w}_{t}^{\prime}+a_{t} \hat{K}_{t}+\left(1-a_{t}\right) \hat{L}_{t}
$$

But, as we noted above, empirically, constant-price monetary data have to be used for output and the capital stock and it is here that an insurmountable difficulty arises. Equation (1) using these data becomes:

$$
V_{t}=f\left(J_{t}, L_{t}, t\right)
$$

where $V$ and $J$ are constant-price value added and the constant-price monetary value of capital stock, respectively. ${ }^{8}$

From the national accounts, the following identity must always hold:

$$
V_{t} \equiv r_{t} J_{t}+w_{t} L_{t} \equiv \Pi_{t}+W_{t}
$$

where $r$ is the rate of profit (a pure number) $)^{9}$ and $w$ is the average real wage rate measured in monetary terms. $V$ is value added and $J$ is the value of the capital stock, both measured in constant prices. $J$ is usually calculated by the perpetual inventory method. In other words, the sum of total profits $(\Pi)$ and the total compensation of labour ( $W$ ) must, by definition, equal value added. Equation (7) can be written in growth rates as:

(8) We use $V$ and $J$ for output and capital measured in monetary values and $Q$ and $K$ for when they are measured using homogenous physical units.

(9) It is calculated as $r t \equiv(V t-w t L t) / J t$ 


$$
\hat{V}_{t} \equiv a_{t} \hat{r}_{t}+\left(1-a_{t}\right) \hat{w}_{t}+a_{t} \hat{J}_{t}+\left(1-a_{t}\right) \hat{L}_{t}
$$

But it should be noted that equation (8) does not require any of the neoclassical assumptions used to derive equation (5). Thus, equation (5), when expressed using monetary values for output and capital as equation (8), must always hold by virtue of the identity.

Neoclassical production theory generally specifies a specific functional form for equations (1) and (6), such as a Cobb-Douglas, CES, or translog production function. But this does not affect the argument. If equation (8) is integrated with respect to time, we derive the result, purely as a result of a mathematical transformation, that at time $\tau$ :

$$
V_{\tau} \equiv B_{o} r_{\tau}^{a_{\tau}} w_{\tau}^{\left(1-a_{\tau}\right)} J_{\tau}^{a_{\tau}} L_{\tau}^{\left(1-a_{r}\right)}
$$

where $B$ is the constant of integration, equal to $a_{\tau}^{-a_{\tau}}\left(1-a_{\tau}\right)^{-\left(1-a_{\tau}\right)}$. The shares are constant because only one point of time is being considered. We may illustrate this equivalence expressed in equation (9) by using data for the United Kingdom for 1990 (the exact year is immaterial), and calculating the level of output both from the identity given by equation (7) and equation (9). The results are reported in Table 1 where it can be seen that they both give exactly the same answer. Thus, at any point of time, a Cobb-Douglas will always give a good fit to the data simply as an alternative mathematical way of writing the identity.

Table 1

\begin{tabular}{|c|c|}
\hline Value added $(V)$ & $£ 519,089$ million \\
\hline Rate of profit $(r)$ & 0.0988 \\
\hline Capital Stock $(J)$ & $£ 1,540,000$ million \\
\hline Wage rate $(w)$ & $£ 13,017.72$ \\
\hline Total persons employed $(L)$ & 28.189 million \\
\hline Capital-output ratio $(\mathrm{J} / \mathrm{V})$ & 2.9667 \\
\hline Capital's share $(a)$ & 0.2931 \\
\hline Labour's share $(1-a)$ & 0.7069 \\
\hline$a^{-a}$ & 1.4329 \\
\hline$(1-a)^{-(1-a)}$ & 1.2779 \\
\hline \multicolumn{2}{|c|}{$\begin{array}{l}\text { The Two Accounting Identities: } \\
\text { (i) } \boldsymbol{V} \equiv \boldsymbol{r} \boldsymbol{J}+\boldsymbol{w} \boldsymbol{L} \\
£ 519,089 \text { million } \equiv(0.0988) \times(£ 1,540,000 \text { million })+(£ 13,017.72) \times(28,189 \text { million }) \\
\text { (ii) } V \equiv\left[a^{-a}(1-a)^{-(1-a)} r^{a} w^{(1-a)}\right] J^{a} L^{(1-a)}=A K^{a} L^{(1-a)} \\
£ 519,089 \text { million } \equiv(1.433) \times(1.278) \times(0.507)(£ 810.149) \times(£ 3,733.897) \times(184,697.63)\end{array}$} \\
\hline
\end{tabular}

UK total output. Selected macroeconomic variables for 1990 in current prices 
If we use cross-industry or cross-regional data and estimate $V_{i t}=A J_{i t}^{\alpha} L_{i t}^{\beta}$ (where $i$ denotes the $i^{\text {th }}$ industry or region) in logarithmic form, it follows that we should find an almost perfect fit to the extent that the variation in the logarithm of wage rate and the rate of profit is small and the factor shares do not greatly differ across observations. This is precisely what Douglas's regressions in the 1930s found, with the coefficients on capital and labour almost identical to their factor shares (Douglas, 1948). He concluded that this proved the neoclassical theory of distribution and refuted the Marxian theory (Douglas, 1976), although, of course, this result is purely an artefact of the accounting identity.

Turning to time-series estimation, a stylised fact is that there is no discernible trend in the rate of profit over long periods of time and the growth of the real wage grows at roughly a constant rate. Hence, the identity given by equation (9) may be expressed as:

$$
V_{t} \equiv r_{t} J_{t}+w_{t} L_{t} \equiv A_{o} e^{\lambda t} K_{t}^{a} L_{t}^{(1-a)}
$$

where $\lambda=(1-a) \hat{w}$. The right-hand side of equation (10) resembles the CobbDouglas relationship, although it is still nothing more than an alternative way of writing the accounting identity.

But, if our argument is correct, why do not estimations of aggregate production functions always give good statistical fits? The fact that they do not may give the impression that they are actually behavioural equations. The poor statistical fits could be due to two reasons. First, factor shares may vary considerably over the estimation period and, secondly, the path over time of the weighted rate of profit and the wage rate may not be accurately proxied by a linear time-trend in the log-linear specification of the Cobb-Douglas (or a constant in the specification in terms of growth rates). Empirically, the latter usually proves to be the correct explanation, and this can result in significant bias on the coefficients on the capital and labour variables. It can also be responsible for suggesting that there are increasing returns to scale. But the statistical fit of the transformation of the identity given by, for example, the last expression in equation (10) or the translog, can always be improved by the introduction of a suitable non-linear time trend. (There is nothing in neoclassical production theory that says technical change has to be a linear function of time.) Alternatively, including a suitable capacity utilisation variable or adjusting the capital and labour inputs for the intensity of use can have the same effect. (Felipe and McCombie, 2005a).

If factor shares vary over time, then a functional form that is more flexible than the Cobb-Douglas (such as a Box-Cox transformation, which turns out to be similar to the CES) could always be used (e.g., see McCombie, 2000b, Felipe and McCombie, 2001). 


\section{Felipe and McCombie's simulation exercise}

One of the most instructive ways to illustrate the problem posed by the accounting identity and the use of monetary data is through a simulation exercise, where we know both the true underlying micro-production functions in physical terms and in value terms, but the researcher only knows the latter. Felipe and McCombie (2006) used a simulation analysis to show how the estimates of a production function could be totally at variance with the actual micro-economic technology. They used cross-firm data for one year. They show that even when the firm micro-production functions display strong increasing returns to scale, the statistical estimates using monetary data must always imply constant returns to scale.

In their simulation analysis, each firm had a true Cobb-Douglas production function given by:

$$
Q_{i}=A K_{i}^{\alpha} L_{i}^{\beta}
$$

where $Q$ and $K$ are output and the number of capital machines, both measured in physical units. $A$ is the level of technology which was normalised to unity. The technological output elasticities of capital and labour were given by $\alpha=0.9$ (or $0.75 \times 1.2$ ) and $\beta=0.3$ (or $0.25 \times 1.2$ ). It should be noted that the values of the elasticities have deliberately been chosen to be the converse of the values of the factor shares as derived from the national accounts, and multiplied by 1.20 , which is the degree of increasing returns to scale. There were 10 firms and in the simulated data they had different values for $Q, K$, and $L$ and a small error term was introduced to prevent perfect multicollinearity. Equation (11) was estimated using cross-firm data for two pooled periods.

To obtain data in monetary terms it was assumed that the individual firms pursue a simple constant mark-up pricing policy: ${ }^{10}$

$$
p_{i}=(1+\pi) \frac{w L_{i}}{Q_{i}}
$$

and, therefore, the value of output at time $t$ is given by:

$$
V_{i} \equiv p_{i} Q_{i} \equiv(1+\pi) w L_{i} \equiv r J_{i}+w L_{i}
$$

(10) More generally, value added for an industry at current prices is given by the sum of the individual firms' value added, i.e., $P_{t}\left(V_{o}\right)_{t}=P_{t} \sum_{i} p_{i 0} Q_{i t}=\sum_{i}\left(1+\pi_{i t}\right) w_{i t} L_{i t}$ where $P t$ is the price deflator, $(V 0) t$ is value added at time $t$ measured using base-year prices, piO, and $P_{t}\left(V_{o}\right)_{t}$ is value added in current prices at time $t$. It is not normally possible to derive the homogeneous quantities from the published data. The picture is somewhat confused by the tendency for the literature to refer sometimes to the Pt s as "prices" rather than "price deflators", which can perpetuate the illusion that we are dealing with physical quantities. 
where $w$ and $\pi$ are the money wage rate and the mark-up for each firm (both assumed to be constant across firms). $\pi$ is taken as 0.333 which implies that capital's share in value added is $a=1 /(1+\pi)=0.75$ and labour's share is $0.25 . J$ is the constant-price monetary value of the capital stock and is calculated as:

$$
J_{i} \equiv \frac{V_{i}-w L_{i}}{r}
$$

where $r$ was taken to be 0.10 and $w$ was assumed to be constant across firms.

The researcher only has access to the monetary, or value, data and not the physical data. When a Cobb-Douglas production function is estimated using the cross-firm hypothetical data, a very close statistical fit is found (the closeness of fit being determined solely by the error term introduced in the construction of the data). The estimate of capital's output elasticity is 0.25 (and equal to capital's share) and not the "true" value of 0.9 . Conversely the estimate of labour's output elasticity was 0.75 (and equal to its factor share) and not the "true" value of 0.3 . In other words, the estimates of the output elasticities are identical to the relevant factor shares and suggest that the production function exhibits constant returns to scale, even though we know that the true parameters are completely different.

In a second simulation, Felipe and McCombie show that if the true underlying firm production functions have constant returns to scale with $\alpha=0.75$ and $\beta=(1-\alpha)=0.25$, the estimated output elasticities are identical to those found when there are increasing returns to scale (i.e., 0.25 and 0.75 respectively). The only difference is that the value of the intercept is lower. Hence, the impact of increasing returns to scale is being captured by a supposedly higher level of technology.

Consequently, the use of value data can never be used to refute the null hypothesis of constant returns to scale, even when all firms display large returns to scale. Therefore, it comes as no surprise to learn that Oulton and O'Mahony find no evidence that there are increasing returns to UK manufacturing or that the output elasticity of capital is very close to its factor share. We turn next to a consideration of their analysis.

\section{Oulton and O'Mahony's test of "is capital 'special'?”}

The early form of the endogenous growth theory emphasised the particular role of capital accumulation in the growth process. One of the first endogenous growth models, the so-called "linear-in-K model" or $Q=\Lambda K$ model (where $\Lambda$ is a constant) assumed that the externalities associated with capital accumulation were so strong that the aggregate output elasticity of $K$ (sometimes interpreted as broad capital) was unity. While this assumption is now generally accepted as being too 
extreme, it is still hypothesised that capital is 'special', in the sense that its output elasticity is greater than its factor share. This is because capital accumulation induces technical change. Let us assume that firm $i$ has a Cobb-Douglas production function where $Q_{i t}=A_{0} e^{\lambda t} K_{i t}^{\alpha} L_{i t}^{(1-\alpha)}$ and the output elasticities equal the factor shares, $\alpha=a$ and $(1-\alpha)=(1-a)$. In other words, there is perfect competition and factors are paid their marginal products. The rate of technical change is partly determined at the industry level by the growth of the total capital stock, for example, through a learning-by-doing process (Arrow 1962):

$$
\lambda_{t}=\tilde{\lambda}+\psi \hat{K}_{t}
$$

where $\tilde{\lambda}$ is the rate of exogenous technical change and $\psi$ measures the extent to which the growth of the aggregate capital stock induces technical change. The growth of the industry capital stock, consequently, generates a positive externality in that a faster rate of growth of it induces a faster growth of technical change. As it is an externality, it is possible to retain the assumption of perfect competition.

Ignoring aggregation problems and summing across firms we obtain $Q_{t}=A_{0} e^{\tilde{\lambda} t} K_{t}^{(\alpha+\psi)} L_{t}^{(1-\alpha)}$, where the output elasticity of aggregate capital $(\alpha+\psi)$ exceeds its factor share $(a)$. Oulton and O'Mahony (1994) undertook two tests to determine whether or not the coefficient on capital significantly departed from the value of its factor share.

They used cross-industry UK manufacturing data expressed in growth rates for 124 industries and considered the period 1954-1986, broken down into 8 sub-periods, and 2 longer combinations of these sub-periods. They use gross output, rather than value added, but this does not affect in any way the criticisms of the aggregate production function discussed above.

\section{The first test}

In the first test, Oulton and O'Mahony start with the definition of multifactor productivity growth (MFPG) (which is what they term total factor productivity growth) "actually being measured" as:

$$
M F P G_{i t} \equiv \hat{Y}_{i t}-\left(\theta_{J i t} \hat{J}_{i t}+\theta_{L i t} \hat{L}_{i t}+\theta_{M i t} \hat{M}_{i t}\right)
$$

where the $\theta$ s are the factor shares, $\hat{Y}$ is gross output and $\hat{M}$ is the growth of intermediate inputs or materials, both measured in constant-price monetary values. The other variables are as defined above. The factor shares by definition must sum to unity, i.e., $\theta_{J i t}+\theta_{L i t}+\theta_{\text {Mit }} \equiv 1$. By "actually being measured", Oulton and O'Mahony mean that equation (16) is calculated using factor shares and other 
variables taken from the census of production and other statistical sources (see Oulton; O’Mahony, 1994, p. 186).

They then assume that the "true" rate of total factor productivity growth is given by:

$$
M F P G_{i t}^{*}=\hat{Y}_{i t}-\left(\theta_{L i t}^{*} \hat{L}_{i t}+\theta_{J i t}^{*} \hat{J}_{i t}+\theta_{M i t}^{*} \hat{M}_{i t}\right)
$$

where the $\theta^{*}$ s are the "true" output elasticities of the production function, which need not necessarily equal the factor shares.

In other words, Oulton and O'Mahony assume that each industry has a well-behaved aggregate production function of the general form $Y_{i t}=f\left(A_{i t}, J_{i t}, L_{i t}\right.$, $\left.M_{i t}\right) .{ }^{11}$ Expressing this in growth rates gives:

$$
\hat{Y}_{i t}=\hat{A}_{i t}+\theta_{J i t}^{*} \hat{J}_{i t}+\theta_{L i t}^{*} \hat{L}_{i t}+\theta_{M i t}^{*} \hat{M}_{i t}
$$

where $\hat{A}_{i t}=M F P G_{i t}^{*}$ is the "true" rate of multi-factor productivity growth. ${ }^{12}$

If there is perfect competition and constant returns to scale, the output elasticities will equal the observed factor shares, i.e., $\theta^{*}=\theta$. Moreover, as we noted above, it can be further shown that if, under these assumptions, factors are paid their marginal products, the "true" growth of multi-factor productivity is given by $\operatorname{MFPG}^{*} \equiv \hat{A}_{i t} \equiv \theta_{J i t} \hat{r}_{i t}+\theta_{L i t} \hat{w}_{i t}+\theta_{\text {Mit }} \hat{m}_{i t}$. The variable $\hat{m}$ is the growth of the relative price of intermediate inputs (materials). In other words, the rate of technical change (or total multi-factor productivity growth) is equal to the sum of the growth of real factor prices, each weighted by its factor share.

Subtracting equation (17) from equation (16) gives the equation:

$$
M F P G_{i t} \equiv M F P G_{i t}^{*}+\left(\theta_{J i t}^{*}-\theta_{J i t}\right) \hat{J}_{i t}+\left(\theta_{\text {Lit }}^{*}-\theta_{\text {Lit }}\right) \hat{L}_{i t}+\left(\theta_{M i t}^{*}-\theta_{\text {Mit }}\right) \hat{M}_{i t}
$$

As $M F P G_{i t}^{*}$, the putative correct measure of total factor productivity growth, is unobservable, Oulton and O'Mahony contend that as it differs across industries, it can be proxied by:

$$
M F P G_{i t}^{*}=\eta_{i}+\chi_{t}+\varepsilon_{i t}
$$

where $\eta$ varies across industries, but is constant over time, $\chi$ is constant across industries but varies over time and $\varepsilon$ is a random error. To test whether capital is "special", Oulton and O'Mahony estimated:

(11) Although the industries are at a relatively high level of disaggregation, the production functions are still "aggregate" in that the production function of any one industry uses the summed values of output and the capital stock of the individual firms in that industry.

(12) Ait is often assumed to take the form $A_{i o} e^{\lambda t}$ where $\lambda$ is the constant rate of technical change. 


$$
M F P G_{i t}=c_{i t}+b_{1} \hat{J}_{i t}+b_{2} \hat{L}_{i t}+b_{3} \hat{M}_{i t}+\rho_{i t}
$$

where $c$ denotes generically the intercept term and $\rho$ is the error term. The coefficients are $\mathrm{b}_{1}=\left(\bar{\theta}_{J i t}^{*}-\bar{\theta}_{J i t}\right), \mathrm{b}_{2}=\left(\bar{\theta}_{L i t}^{*}-\bar{\theta}_{L i t}\right)$, and $\mathrm{b}_{3}=\left(\bar{\theta}_{M i t}^{*}-\bar{\theta}_{M i t}\right)$, where the bar denotes the sample average. If the coefficient on $\hat{J}$ (i.e., $\left.\mathrm{b}_{1}=\left(\bar{\theta}_{J i t}^{*}-\bar{\theta}_{J i t}\right)\right)$ is statistically significant and positive, they argue that this shows that the true output elasticity of capital is greater than its factor share. (The same is also true for $\hat{L}$ and $\hat{M}$.) Conversely, if the coefficient is not statistically significant, this demonstrates that capital does not induce any externality effects. Oulton and O'Mahony estimated equation (21) using the UK cross-manufacturing data. They ran the regressions for the 10 sub-periods separately over the period 1954-1986 and found that estimated coefficients $b_{1}, b_{2}$, and $b_{3}$ were nearly always statistically insignificant. Therefore, as the $\theta_{J}^{*} s$ do not significantly differ from the $\theta_{J} s$, they conclude "these results therefore provide no support at all for the view that the role of capital has been understated" (p.162).

But what precisely is the interpretation of equation (21)? Recall that we are using constant-price monetary data and therefore the following accounting identity must always hold:

$$
\begin{aligned}
& \hat{Y}_{i t} \equiv\left(\theta_{J i t} \hat{i}_{i t}+\theta_{L i t} \hat{w}_{i t}+\theta_{M i t} \hat{m}_{i t}\right)+\left(\theta_{J i t} \hat{J}_{i t}+\theta_{L i t} \hat{L}_{i t}+\theta_{M i t} \hat{M}_{i t}\right) \\
& \quad \text { or, } \\
& M F P G_{i t} \equiv\left(\theta_{J i t} \hat{r}_{i t}+\theta_{L i t} \hat{w}_{i t}+\theta_{M i t} \hat{m}_{i t}\right) \\
& \equiv \hat{Y}_{i t}-\left(\theta_{J i t} \hat{J}_{i t}+\theta_{L i t} \hat{L}_{i t}+\theta_{M i t} \hat{M}_{i t}\right)
\end{aligned}
$$

In other words, empirically equations (22), (23a), and (23b) hold exactly, even though there is no underlying aggregate production function. The only reason that we may not find a perfect statistical fit to these equations is that the factor shares differ between the industries and over time. By manipulating the identity we obtain:

$$
M F P G_{i t} \equiv M F P G_{i t}+\left(\theta_{J i t}-\theta_{J i t}\right) \hat{J}_{i t}+\left(\theta_{L i t}-\theta_{L i t}\right) \hat{L}_{i t}+\left(\theta_{M i t}-\theta_{M i t}\right) \hat{M}_{i t}
$$

which is similar to equation (19), but where all the variables are observed, i.e. can be constructed from the data. There is no a priori reason why MFPG (or the observed sum of the weighted growth of the factor prices) should be correlated with the growth of the factor inputs (Salter, 1960). If this is the case and if, following Oulton and O'Mahony, we were to estimate equation (21), we should expect from equation (24) to find that the estimated coefficients $b_{1}, b_{2}$ and $b_{3}$ to be equal to zero. In other words, all that the estimates of the regression of equation 
(21) show is that the observed $M F P G$ is orthogonal to the other regressors (i.e., $\hat{J}, \hat{L}$ and $\hat{M}$ ).

Alternatively, we can also interpret equation (21) as an auxiliary regression between the two sets of regressors in parentheses in the identity given by equation (22). It should be emphasised that all this has nothing to do with an aggregate production function, which, as we have emphasised, does not theoretically exist.

These remarks are confirmed by the results in Table 2, which use pooled data from Oulton and O'Mahony (1994) and panel data estimation. Equation (i) in Table 2 is nothing more than the estimation of the full identity given by equation (23b). The coefficient of $\hat{Y}_{i t}$ should equal unity and the coefficients of the other regressors are the (negative) average values of the factor shares. It can be seen that the estimated coefficients are close to their expected values. But the point to be made is that this regression is not a test of any behavioural hypothesis, but merely illustrates the above argument that is a question of logic. ${ }^{13}$

Equation (21), which Oulton and O'Mahony use to test the externality hypothesis, is derived by excluding $M F P G$ from equation (24) (or, alternatively, $\hat{Y}$ from equation (23b)). The regression is estimated by panel fixed-effects with time and industry dummies. The results are reported in Table 2 as equation (ii). All the coefficients are very close to zero, which is what we would expect solely from the identity. (The coefficients $\hat{L}$ and $\hat{M}$ are statistically significant, but this seems to be purely coincidental. They are not usually significant when the individual sub-periods are regressed. See also the results of Oulton and O'Mahony, (1984, Table 7.1, p. 162).)

To reiterate: all that the results of estimating equation (21) show is that the sum of the weighted growth of the factor prices is orthogonal to the growth of the factor inputs and/or its variation is being captured by the fixed-effects estimation.

An equivalent approach is to regard equation (21) as being derived from equation (23b), when $\hat{Y}$ is excluded from the latter equation. The fact that the estimated coefficients of equation (21) are nearly zero implies that the "auxiliary equation" of regressing $\hat{Y}$ on $\hat{J}, \hat{L}$, and $\hat{M}$ will give estimates of the coefficients that should be approximately equal to the averages of the corresponding factor shares. We explicitly tested this by estimating:

$$
\hat{Y}_{i t}=c_{i t}+b_{4} \hat{J}_{i t}+b_{5} \hat{L}_{i t}+b_{6} \hat{M}_{i t}+\zeta_{i t}
$$

(13) Equation (21) was estimated for each period separately and we found, not surprisingly, very similar results.

Economia e Sociedade, Campinas, v. 17, Número especial, p. 655-675, dez. 2008. 
where $\zeta$ the error term. As we have noted, given the previous results, it is expected that $\mathrm{b}_{4} \cong \bar{\theta}_{J i t}, \mathrm{~b}_{5} \cong \bar{\theta}_{L i t}$ and $\mathrm{b}_{6} \cong \bar{\theta}_{\text {Mit }}$. The regression results are reported in Table 2, equation (iii). (A neoclassical economist would regard this as a direct estimate of the production function with the value of the intercept measuring the rate of technical progress.) Because $\hat{L}, \hat{K}$, and $\hat{M}$ are large components of $\hat{Y}$, it is not surprising the $\mathrm{R}^{2}$ is so high (0.790). The estimated coefficients of the growth of the factor inputs are, as expected, close to their respective factor shares. But all this shows is that dropping MFPG from the identity given by equation (22) does not significantly bias the estimates of the coefficients of the other variables in the identity. This is also confirmed by Table 2, equation (ii).

Table 2

Estimating various specifications of the identity; Dependent variable $M F P G$ (equations (i) and (ii)) and output growth (equation (iii)), pooled sub-periods, 1954-1986

\begin{tabular}{|c|c|c|c|}
\hline & \multicolumn{2}{|c|}{$M F P G$} & \multirow{2}{*}{$\begin{array}{c}\hat{Y} \\
\text { (iii) }^{\mathrm{a}}\end{array}$} \\
\hline & (i) & $(\mathrm{ii})^{\mathrm{a}}$ & \\
\hline$\hat{Y}_{i}$ & $0.817(55.12)$ & - & - \\
\hline$\hat{J}_{i}$ & $-0.095(-6.53)$ & $-0.015(-0.33)$ & $0.153(3.13)$ \\
\hline$\hat{L}_{i}$ & $-0.202(-20.85)$ & $0.061 \quad(1.95)$ & $0.311(9.27)$ \\
\hline$\hat{M}$ & $-0.493(-37.49)$ & $-0.040 \quad(-1.82)$ & $0.558(23.70)$ \\
\hline$R^{2}$ & 0.751 & 0.145 & 0.790 \\
\hline
\end{tabular}

Notes: t-statistics in parentheses. Regressions (ii) and (iii) include a constant. ${ }^{a}$ Fixed-effects estimation, time and industry dummies.

Source: Data from Oulton and O’Mahony (1994).

Memorandum item: Shares of inputs in gross output (figures in parentheses are the standard deviations); capital 0.141 (5.5); labour, 25.9 (8.2) and intermediate inputs, 60.0 (8.5).

In summary, these estimates cannot tell us anything about whether or not the putative aggregate output elasticities (which theoretically do not exist) equal their corresponding shares. This test can also shed no light on the degree of returns to scale, as the identity guarantees that the estimates of the putative output elasticities will always equal the factor shares and hence sum to unity. (The coefficients, in fact, sum to 1.022.) This assumes, as discussed and confirmed above, that MFPG is orthogonal to $\hat{J}, \hat{L}$, and $\hat{M}$ and/or its variation is being adequately by the two-way fixed effects in the panel regression. However, it should be emphasised that our argument in no way depends upon this condition. If MFPG and the variables $\hat{J}, \hat{L}$, and $\hat{M}$ were correlated, the estimates of the factor shares would be biased and their sum may be statistically significantly different from unity. There might be an economic explanation for this, but it would have nothing to do with an aggregate production function. What is determining the 
goodness of fit, and the (biased) estimates of the coefficients (the factor shares), is still the identity, albeit misspecified by the omission of MFPG.

The results simply show that there is no statistically significant relationship between the sum of the weighted growth of factor prices and the growth of factor inputs and nothing more.

\section{The second test}

Oulton and O'Mahony also proposed a second test, which is equally flawed, of whether or not capital is special. In fact, it is merely a different specification of the first test and does not really tell us anything new. They start with the identity: ${ }^{14}$

$$
\left(\hat{Y}_{i t}-\hat{L}_{i t}\right) \equiv M F P G_{i t}+\theta_{J i t}\left(\hat{J}_{i t}-\hat{L}_{i t}\right)+\left[\theta_{J i t}+\theta_{L i t}+\theta_{M i t}-1\right] \hat{L}_{i t}+\theta_{M i t}\left(\hat{M}_{i t}-\hat{L}_{i t}\right)(26)
$$

and use two-way fixed effects to model MFPG. Consequently, they estimate:

$$
\left(\hat{Y}_{i t}-\hat{L}_{i t}\right)=c_{i t}+b_{7}\left(\hat{J}_{i t}-\hat{L}_{i t}\right)+b_{8} \hat{L}_{i t}+b_{9}\left(\hat{M}_{i t}-L_{i t}\right)+\xi_{i t}
$$

If the theory underlying the calculation of MFP growth rates is correct, we would expect that the estimated coefficients on $\hat{J}_{i t}$ and $\hat{M}_{i t}$ in a panel regression would be approximately equal to the sample average of the value shares for capital and intermediate input respectively and that the coefficient on $\hat{L}_{i t}$ would be equal to zero, since the value shares sum to one. One the other hand, if standard theory understates the role of capital and if increasing returns exist, then the sum of the elasticities exceeds one (that is $\theta_{J i t}+\theta_{L i t}+\theta_{M i t}>1$ ), and coefficient on $\hat{L}_{i t}$ is positive. Also, the coefficient on capital should be significantly larger than capital's value share (Oulton; O'Mahony, 1984, p. 163. Their notation has been changed to that used in this paper).

They find that the regression results "all reject the hypothesis of a special role for capital" (p. 165). The coefficient on $\hat{L}_{i t}$ is never statistically significant and the coefficients on $\hat{J}_{i t}$ and $\hat{M}_{i t}$ are very close to their sample average shares.

The fallacy of this interpretation may be straightforwardly shown, as the problem is that the results are once again driven by the accounting identity. All that the results of equation (28) show is that once again either the effect of MFPG, or $\left(\theta_{J i t} \hat{r}+\theta_{L i t} \hat{w}+\theta_{M i t} \hat{m}\right)$, is being captured by the fixed effects and/or MFPG is orthogonal to the other regressors.

(14) They are perfectly well aware that this is an identity which arises because of the way MFPG is constructed (see equation (16)), but this is not the accounting identity. Moreover, and here is the big difference, they assume that there is an underlying production function that can be estimated using constant-price monetary data and their interpretation of their results are predicated on this. (See Oulton; O'Mahony, 1984, p. 160.) 
Given the previous results, it is not surprising that Oulton and O'Mahony find the estimates of the coefficients of $(\hat{J}-\hat{L})$ and $(\hat{M}-\hat{L})$ are not significantly different from the average factor shares and the coefficient on $\hat{L}$ is not significantly different from zero. ${ }^{15}$ Indeed, estimating this regression is superfluous given the previous results.

This is illustrated by Table 3. Equation (i) reports the full identity, where it can be seen that the coefficient on MFPG is slightly smaller than the predicted 1.00. Nevertheless, the estimated shares of capital (0.15) and of intermediate inputs $(0.60)$ are very close to the average values over the 8 sub-periods $(0.15$ and 0.59 respectively). The coefficient of the growth of the employment is not statistically significant, which is in accord with equation (27).

Table 3

Estimating Various Specifications of the Identity: Dependant Variable

\begin{tabular}{l|c|c}
\multicolumn{1}{c}{$\left(\hat{Y}_{i t}-\hat{L}_{i t}\right)$, pooled sub-periods $1954-1986$} \\
\hline$M F P G$ & $(\mathrm{i})$ & (ii) $^{\mathrm{a}}$ \\
\hline$\left(\hat{J}_{i t}-\hat{L}_{i t}\right)$ & $0.913(55.12)$ & - \\
\hline$\hat{L}_{i t}$ & $0.145(9.68)$ & $0.153(4.80)$ \\
\hline$\left(\hat{M}_{i t}-\hat{L}_{i t}\right)$ & $0.001(-0.05)$ & $0.022(0.52)$ \\
\hline$R^{2}$ & $0.597(56.53)$ & $0.558(23.70)$ \\
\hline
\end{tabular}

Notes: t-statistics in parentheses. Equation (ii) includes a constant. ${ }^{\mathrm{a}}$ Fixed-effects estimation, time and industry dummies.

Source: Data from Oulton and O'Mahony (1994).

As we know from the above results that $M F P G$ is almost orthogonal to the growth of factor inputs and/or its variation captured by the two-way effects in the estimation procedure, dropping it from the regression does not greatly bias the coefficients of the included variables. This is confirmed by Table 3, equation (ii), where the coefficients on $\hat{J}$ and $\hat{M}$ are close to their factor shares and the growth of the labour input is again statistically insignificant. But equation (27) is simply a re-specification of equation (25) where $\hat{L}$ has been subtracted from both sides of the equation.

The coefficients of $\hat{J}$ and $\hat{M}$ in equations (25) and (27) should each be exactly equal (i.e., the estimates of $b_{4}=b_{7}$ and $b_{6}=b_{9}$ ). The estimate of coefficient

(15) Their results are reported in Oulton and O'Mahony, (1984, Table 7.2, p. 164 and Table 7.3, p. 165). When they split the capital stock into plant and machinery, buildings, and vehicles, they find the coefficients of these variables are usually statistically insignificant. This result is probably due to the large disparities between industries in the shares in output of these three types of the capital stock, preventing any precise estimation of the average shares. 
on $\hat{L}, \mathrm{~b}_{8}$, should equal the estimate of $\mathrm{b}_{4}+\mathrm{b}_{5}+\mathrm{b}_{6}-1$, which is also the case. The regression of equation (27) conveys no new information in addition to that contained in the regression results of equation (25) i.e., Table 2, equation (iii). Similarly, both regressions can tell us nothing about the underlying technological conditions of production.

To summarise: these results cannot be used to infer that capital is not special, as Oulton and O'Mahony and Crafts et al., do, the latter in the papers cited above. The data cannot tell us either way.

\section{Conclusions}

The conclusions of this paper may be summarised as follows.

The literature on aggregation shows that aggregate production functions do not exist in the sense that the theoretical conditions required to aggregate micro-production functions into a well-behaved aggregate production function are so stringent that in all probability actual economies do not satisfy them. Indeed, intuition would suggest that it makes little sense to aggregate the data for such diverse industries as, say, textiles and petrochemicals and talk about the "aggregate elasticity of substitution" of this new hybrid industry.

The sole reason why the estimation of production functions using constant-price monetary data yields what may be seen as plausible results is the existence of the underlying accounting identity. If shares are roughly constant then the Cobb-Douglas "production function" may give an exceptionally good fit to the data, but the causation is from the stability of the factor shares to the CobbDouglas relationship, and not vice versa.

The underlying accounting identity ensures that it is always possible to get a good statistical fit to a constant-price monetary data production function where estimates of the "output elasticities" are not statistically different from the values of the factor shares. This has been illustrated by a consideration of Oulton and O'Mahony's two tests using panel data of UK manufacturing industries.

The argument is not affected if factor shares vary over time. All that one needs is a more flexible functional form (such as translog) to give a good fit to the data. These conclusions are the result of logic and not of subjective interpretation. Consequently, and it is surprising to see the continued uncritical widespread use of the aggregate production function in both empirical and theoretical studies.

\section{References}

AGHION, P.; HOWITT, P. Endogenous growth theory. Cambridge MA: MIT Press, 1998. 
ARROW K. J. The economic implications of learning by doing. Review of Economic Studies, v. 29, p. 155-173, 1962.

BARRO, R. J., SALA-I-MARTIN, X. (1995). Economic growth. $2^{\text {nd }}$. ed. New York: McGraw Hill, 2004.

BEAN, C.; CRAFTS, N. F. R. British economic growth since 1945. In: CRAFTS, N.; TONIOLO, G. (Ed.). Economic growth in Europe since 1945. Cambridge: Cambridge University Press, 1996.

BRONFENBRENNER, M. Production functions: Cobb-Douglas, interfirm, intrafirm. Econometrica. v. 12, p. 35-44, 1944.

CRAFTS, N. F. R. Post-neoclassical endogenous growth theory: what are its policy implications? Oxford Review of Economic Policy, v. 12, p. 30-46, 1996.

; TONIOLO, G. Postwar growth: an overview. In: CRAFTS, N.; TONIOLO, G. (Ed.). Economic growth in Europe since 1945. Cambridge: Cambridge University Press, 1996.

COHEN, A. J.; HARCOURT, G. C. Whatever happened to the capital controversies? Journal of Economic Perspectives, v. 17, p. 199-214, 2003 a.

; _ [Cambridge capital controversies] Response. Journal of Economic Perspectives, v. 17, p. 227-232, 2003 b.

CRAMER, J. S. Empirical econometrics. Amsterdam: North-Holland, 1969.

DOUGLAS, P. H. Are there laws of production? American Economic Review, v. 38, p. 141, 1948.

DOUGLAS, P. H. The Cobb-Douglas production function once again: its history, its testing, and some new empirical values. Journal of Political Economy, v. 84, p. 903-915, 1976.

FELIPE, J. Endogenous growth, increasing returns, and externalities: an alternative interpretation of the evidence. Metroeconomica, v. 52, p. 391-427, $2001 \mathrm{a}$.

Aggregate production functions and the measurement of infrastructure productivity: a reassessment. Eastern Economic Journal, v. 27, p. 323-344, 2001 b.

; ADAMS, F. G. 'A theory of production'. The estimation of the Cobb-Douglas function: a retrospective view. Eastern Economic Journal, v. 31, p. 427-445, 2005.

; FISHER, F. M. Aggregation in production functions: what applied economists should know. Metroeconomica, v. 54, p. 208-262, 2003.

; HOLZ, C. Why do aggregate production functions work? Fisher's simulations, Shaikh's identity, and some new results. International Review of Applied Economics, v. 15, p. 261-285, 2001.

; MCCOMBIE, J. S. L. The CES production function, the accounting identity, and Occam's razor. Applied Economics, v. 33, p.1221-1232, 2001.

; _ Methodological problems with neoclassical analyses of the East Asian miracle. Cambridge Journal of Economics, v. 54, p. 695-721, 2003. 
FELIPE, J.; MCCOMBIE, J. S. L. How sound are the foundations of the aggregate production function. Eastern Economic Journal, v. 31, p. 467-488, $2005 \mathrm{a}$.

; __ Why are some countries richer than others? A sceptical view of Mankiw-Romer-Weil's test of the neoclassical growth model. Metroeconomica, v. 56, p. 360-392, 2005b.

; _ The tyranny of the accounting identity: growth accounting revisited. International Review of Applied Economics, v. 20, p. 283-299, 2006.

; _ $\quad$ On the rental price of capital and the profit rate: the Perils and Pitfalls of total factor productivity growth. Review of Political Economy, v. 19, p. 317345, 2007.

FISHER, F. M. Aggregation. Aggregate production functions and related topics / Ed. by J. Monz. London: Harvester Wheatsheaf, 1992.

Aggregate production functions - A pervasive, but unpersuasive, fairytale. Eastern Economic Journal, v. 31, p. 489-491, 2005.

FRIEDMAN, M. The methodology of positive economics. In: FRIEDMAN, M. (Ed.). Essays in positive economics. Chicago: Chicago University Press, 1951.

HAACHE, G. The theory of economic growth: an introduction. London: Macmillan, 1979.

INTRILIGATOR, M. D. Econometric models, techniques and applications. EnglewoodCliffs, NJ: Prentice Hall, 1978.

JONES, C. S. (1998). Economic growth. $2^{\text {nd }}$. ed. New York: WW Norton, 2002.

JONES, H. G. An introduction to modern theories of economic growth. Middlesex: Nelson, 1975.

MCCOMBIE J. S. L. Does the aggregate production function imply anything about the laws of production? A note on the Simon and Shaikh critiques. Applied Economics, v. 19, p. 1121-1136, 1987.

. 'Are there laws of production?': an assessment of the early criticisms of the Cobb-Douglas production function. Review of Political Economy, v. 10, p. 141-173, 1998a.

Paradigms, rhetoric, and the relevance of the aggregate production function. In: ARESTIS, P. (Ed.). Method, theory and policy in Keynes. Essays in honour of Paul Davidson, v. III. Aldershot: Edward Elgar, 1998b.

- Regional production functions and the accounting identity: a problem of interpretation. Australasian Journal of Regional Studies, v. 6, p. 133-155, 2000.

. The Solow residual, technical change and aggregate production functions. Journal of Post Keynesian Economics, v.23, p. 267-297, 2000-2001. (Errata, v. 23, n. 3, p. 544).

What do aggregate production functions show? Second thoughts on Solow's 'second thoughts on growth theory"'. Journal of Post Keynesian Economics, v. 23, p. 589615, 2001. 
MCCOMBIE J. S. L.; DIXON, R. Estimating technical change in aggregate production functions: a critique. International Review of Applied Economics, v. 5, p. 24-46, 1991.

; THIRLWALL, A. P. Economic growth and the balance-of-payments constraint. Basingstoke: Macmillan, 1994.

MARSHAK, J.; ANDREWS, W. H. Random simultaneous equations and the theory of production. Econometrica, v. 12, p.143-205, 1944.

MADDISON, A. Growth and slowdown in advanced capitalist economies: techniques of quantitative assessment. Journal of Economic Literature, v. 25, p. 649-698, 1987.

NADIRI, I. M. Some approaches to the theory and measurement of total factor productivity: a survey. Journal of Economic Literature, v. VIII, p. 1137-1177, 1970.

OULTON, N.; O'MAHONY M. Productivity and growth. A study of British industry, 1954-1986. Cambridge: Cambridge University Press, 1994.

PHELPS, Brown E. H. The meaning of the fitted Cobb-Douglas function. Quarterly Journal of Economics, v. 71, p. 546-560, 1957.

ROBINSON, J. V. The production function and the theory of capital. Review of Economic Studies, v. 21, p. 81-106, 1953-1954.

SALTER, W. E. G. (1960). Productivity and technical change. $2^{\text {nd }} \cdot$ ed. Cambridge: Cambridge University Press, 1966.

SAMUELSON, P. A. Paul Douglas's measurement of production functions and marginal productivities. Journal of Political Economy, v. 87, p. 923-939, 1979.

SHAIKH, A. Laws of production and laws of algebra, the Humbug production function. Review of Economics and Statistics, v. 56, p. 115-120, 1974.

. Laws of production and laws of algebra: Humbug II. In: NELL, E. J. (Ed.). Growth, profits and property. Cambridge: Cambridge University Press, 1980.

Nonlinear dynamics and pseudo-production functions. Metroeconomica, v. 31, p. 447-466, 2005.

SIMON, H. A. On parsimonious explanations of production relations. Scandinavian Journal of Economics, v. 81, p. 459-474, 1979a.

SIMON, H. A. Rational decision-making in business organizations. American Economic Review, v. 69, p.493-513, 1979b. (Nobel Memorial Lecture, 8 Dec. 1997.)

; LEVY, F. K. A note on the Cobb-Douglas function. Review of Economic Studies, v. 30, p. 93-94, 1963.

SOLOW, R. M. Laws of production and laws of algebra: the humbug production function: a comment. Review of Economics and Statistics, v. 56, p. 121, 1974.

Second thoughts on growth theory. In: STEINHERR, A.; WEISERBS, D. (Ed.). Employment and growth: issues for the 1980s. Dordrecht: Martinus Nijhoff Publishers, 1987.

TEMPLE, J. The new growth evidence. Journal of Economic Literature, v. 38, p. 112$156,1999$. 
Why the data tell us nothing about the importance of increasing returns to scale and externalities to capital

VALDÉS, B. Economic growth theory, empirics and policy. Cheltenham: Edward Elgar, 1999.

WAN, H. Y. Economic growth. New York: Harcourt Brace Jovanovich, 1971.

WALLIS, K. F. Topics in applied econometrics. London: Gray-Mills Publishing, 1979.

WALTERS, A. A. Production and cost functions. Econometrica, v. 31, p. 1-66, 1963.

WEIL, D. N. (2004). Economic growth. $2^{\text {nd }}$. ed. Addison-Wesley, 2008. 